\title{
The Evolutionary of Geographical Research in Amitav Ghosh's Novel the Hungry Tide-A Critical Testimony
}

\author{
Dr. Venkateswarlu Yesapogu, M.A., M.Phil, PhD. Head \\ Dept of English, Principal FAC in V.V. \& M Gov't Aided Degree College \\ Ongole, Prakasam D.T., A.P. India \\ Yvghosh.yvghosh@gmail.com
}

\begin{abstract}
Amitav Ghosh crafted another fascinating and ambitious novel, The Hungry Tide( 2004), about a place that remains remote and exotic to many readers and about a community of people who live on the periphery of the Indian subconscious, the dispossessed of the tide country. The Hungry Tide does not have the grand historical sweep of The Glass Palace, but it is a layered and moving book in which Ghosh creates a broadly realistic portrayal of the Sundarbans that acts as a counterpoint to the dreamlike, unknowable mangrove swamps found in an allegorical section of Salman Rushdie's Midnight's Children. In his masterly story-telling and use of vividly realized details, the mysterious and enchanting Sundarbans-with the mangroves and man-eating predators, fishes and dolphins, tempests and tides, myth, culture and history-come alive as interfaces in Ghosh's fiction. The pre-historic rain forest is not here merely a backdrop of the human drama but a living presence, one of its major characters. In fact, nothing happens in the book but that the Sundarbans makes it happen.
\end{abstract}

Much of Ghosh's writing meditates on the arbitrary and vexing nature of national borders. This book is surely obsessed with more personal divisions between men and women. One of the major elements of this novel's plot is the story of Kanai's growing relationship with Piya. Another is Piya's developing understanding of Fokir. A third is Kanai's gradual transformation through his reading of his uncle's account of the "Morichjhapi incident" from some thirty years ago. After The Glass Palace's complex family structure stretching over several generations, The Hungry Tide seems almost intimate. Nonetheless, it shares Ghosh's concern for the individual against a broader historical or even, in this case, geographical - backdrop.

Keywords: Hungry tide, Sunderbans, remote land, cyclone, border, historical, Geographical testimony.

\section{INTRODUCTION}

This book is divided into two broad sections: "The Ebb: Bhata" and "The Tide: Jowar," The Hungry Tide is set in the Sudarbans, an archipelago of hundreds of scattered islands, some densely populated while others completely uninhabited, at the mohona of several rivers in the Bay of Bengal. "The islands are," the novelist says, "The trailing threads of India's fabric, the ragged fringes of her sari, the achol that follows her, half - wetted by the sea" (6). Interposed between the sea and the plains of Bengal this archipelago stretches -for almost three hundred kilometers -from the HooghlyRiver in West Bengal to the shores of the Meghna in Bangladesh. It is called 'India's doormat, the threshold of a teeming subcontinent' (50). For hundreds of years the foreigners -the Arakanese, the Khmer, the Dutch, the Portuguese, the Malays, the English - have taken this eastern route to the Gangetic heartland. It is an untamed area where the Ganga empties into the Bay, where there is no border to divide fresh water and salt, and the boundaries between land and water are always mutating, creating a diverse natural habitat where tigers and snakes, crocodiles and sharks roam free.

This is a place where floods continually inundate the land and whole forests lift their heads above the tides and the disappear. It is liquid landscape where surfacing cyclones can wipe out thousands of lives with the flick of one giant wave, where animals and humans, myth and reality imperceptive merge into each other in a ritual struggle for survival. 'Midwifed by the Moon' (8) and sculpted by colossal tides and the titanic storms, this estuarine region -known variously as a Sudarbans, after the sundari tree, Heriteria minor, Badaban after the mangroves, and bhatirdesh, the tride country -is home to the Royal Bengal Tigers and the Irrawaddy dolphins, Orcaellabrevirostris. Some even call it attherobhatirdesh, the land of eighteen tides. The place was mentioned in the record books of the 
Mughal emperors and in Francois Bernier's Travels in the Mughal Empire. The multiplicity of names for the Sundarbans is a metaphor for its ephemerality. The land itself is inconstant, subject radical transformation as a result of late summer storms and tide water. Whole islands are washed away by the cyclones that sweep in form the Bay with huge tidal surges. Thousands of human beings and animals routinely die here in natural disaster. As a character in the novel puts it: "in the tide country, transformation is the rule of life: rivers stray from week to week and islands are made and unmade in days" (224). Here, for hundreds of years, only the truly dispossessed braved the tigers, crocodiles and sharks to eke out a precarious existence from the mud and the forest produce.

At the beginning of the twentieth century, a rich and visionary Scotsman, Sir Daniel Mackinnon Hamilton, who believed in the dictum 'labor conquers everything,' founded a Utopian settlement where people of all races, classes and religions could live together 'without petty social distinctions and differences' (53). He wanted to establish a new society, a new kind country: "It would be a country run by co-operatives.... Here people wouldn't exploit each other and everyone would have a share in the land" (52). The news was spread and people from Orissa, Eastern Bengal and Santhal Parganas rushed to the tide country in search of free land. Villages sprouted on the islands and Hamilton gave them names. Everything was provided for them: electricity, telephone, bank and currency. It was a magnificent dream dreamed by a leading capitalist of Colonial India: "He dreamed of a place where men and women could be farmers in the morning, poets in the afternoon and carpenters in the evening" (53). But, unfortunately, his dream did not come true. The tide country was not yet ready for Hamilton's progressive ideas. His memory is preserved in the names of the islands given by him and the estate he had founded.

On the similar pattern of other novels, Amitav Ghosh shows here an anthropologist's fascination for the place and its people and the stories they tell -the local myths and legends that subvert the official versions of history and religion. The tide country people have an epic narrative of origins which the pass on orally from generation to generation. The Hungry Tide is a powerful evolutionary story of this region and its people. The setting, unlike in The Glass Palace, is geographically limited, yet vast in its implications of some wider global concerns, like preservation of endangered species, environmentalism versus survivalism, rights of the homeless and the dispossessed.

The theme is primarily about Indo-American cytologist Piya Roy, who cannot even speak her mother tongue, comes to the tide country of the Sundarbans in Bengal to study river dolphins. She is drawn into a curious love triangle involving the local fisherman Fokir, who helps her to locate dolphins in remote Garjontola pool; and Kanai Dutt, a prosperous and proud owner of a translation business in New Delhi who is visiting his Aunt, Nilima. Years earlier, Nilima's husband, the Marxist teacher Nirmal had become involved in aiding and assisting a displaced refugee population who had settled on the Sundarbans island of Morichjhapi. Among these refugees was Kusum, mother of a then infant Fokir. In another love triangle of sorts, Nirmal had been motivated to help the refugees out of love for Kusum, who was also being assisted by Horen. The two stories- one of the notebook and the other of Kanai, Piya and Fokir-that make up the narrative structure of the novel, are unfolded in a braided manner in alternate chapters.

Kanai's narrative brings to life the character of his uncle, Nirmal Bose, who is dead before the story begins. At present Kanai has returned to the tide country from Delhi to read a 'lost journal', written by his now dead uncle, Nirmal. This recounts the final hours before MorichjahapiIsland was forcibly cleared of refugees by police and military troops following a protracted siege. Kusum was killed in the resulting massacre. At the conclusion of the novel, Fokir also is killed-in a cyclone, while guiding Piya on one of the tide country's many remote waterways. In an odd resolution, Piya decides to continue her aquatic research in the tide country, and asks Nilima to help her set up a research trust, as a memorial to Fokir. She also asks Kanai to be her partner in this venture.

The action of The Hungry Tide is set on the Sundarbans island of Lusibari. When Kanai first invites Piya to visit his Aunt's hostel on Lusibari, he explains that the name itself is a relic of a bygone, colonial era: you would be surprised how many places in the Sundarbans have names that come from English . . . Lusibari just means "Lucy's house." The Lucy in question was Lucy Hamilton, daughter of a Scottish shipping magnate, Sir Daniel Hamilton, in the first half of the twentieth century. She was on her way here from the far and of Europe, when her ship capsized. She never got to see the house but because it had been built for her, people; used to call it Lusi'r-bari. Then this was shortened to Lusibari and that was how the island took this name.'(40) 
Ghosh chose to set The Hungry Tide in the Sundarbans for several reasons. The tide country is not simply a remote and hostile environment where nature can be studied in the raw. It is also a substantial human environment, where natural phenomena develop through interaction with mankind. It is in fact a zone of several different kinds of interaction, a zone of contact between different cultural, national, ethnic, linguistic and religious communities. It is, in short, a border zone. Kanai explains this to Piya in the following way.

The significance of the tide country is that it is a frontier territory, where different cultures have interacted for centuries. Initially, this takes the form of a particular challenge to a precise phase of European colonial history: the English imperialists are, as it were, the most recent generation of ghosts to have been erased from memory by the encroaching mangrove of the islands. There is a great historical irony in Kanai's description to Piya of how the area was settled in the nineteenth century by British officials serving the Viceroy Lord canning, searching for a suitable location for an eastern port to rival their western port of Bombay. 'They got it in their heads,' he tells her, 'that they needed a new port, a new capital for Bengal-Calcutta's Hooghly River was silting up and its docks, they said, would soon be choked with mud. Jothariti, teams of planners and surveyors, went out and wandered the land, striding about in wigs and breeches, mapping and measuring. And at last on the banks of the Malta they came to a place that caught their fancy, a little fishing village that overlooked a river so broad that it looked like a highway to the sea.' (284)

In Kanai's amused narration of this history of the island, and in his portrayal of the self-important officials in hats and wigs crossing and measuring the land, there is a distinctive mockery of a whole phase of colonial rule. Kanai's narrative assumes the status of a local myth: the stupidity and arrogance of Lord Canning affirms the ongoing dispute of the local population against a certain version of imperial history. In naming, the failed town Canning after the Viceroy and in acknowledging it to be a vassal, or slave, to the Malta River, the buffoonery and eventual defeat of India's former colonial rulers are trumpeted for all time. Kanai's narrative therefore maps out a new kind of cultural geography, in which the relics of the British rule do not only survive as trace elements in place names, but are also transformed into emblems of the end of the British rule.

Whereas Ghosh registers his challenge to the official accounts of imperial history by emblazoning the names of the imperialists' across the very locations associated with their failure, Ghosh registers the challenge to colonial history in a different way. For paradoxically, the result of the success of the imperial development of Bombay into a major commercial and political hub brings its population into a similar relationship to colonial rule as the inhabitants of the tide country in The Hungry Tide. The commercial success of Bombay has resulted in the fishermen, who first inhabited it, being pushed out the periphery of the city, occupying position whose vulnerability, both politically and geographically, resembles that of the refugees who will eventually settle the island of morichjhapi:

The Hungry Tide, the challenge of the dispossessed is registered via the human make-up of the tide country. Each incomer to the country has been compelled by far-away political events to flee their home and seek a new start. Interestingly, the island of Lusibari had first been populated because of a philanthropic colonialist, the Scot Sir Daniel Hamilton, who had bought land from the forestry department in order to give an impoverished rural population a chance to settle new land and begin new agricultural projects. 'Everyone who was willing to work was welcome, S'Daniel said, but on one condition. They could not bring all their petty little divisions and differences. Here there would be no Brahmins or Untouchables, no Bengalis and no Oriyas. Everyone would have to live and work together.' (51)

However, the refugees' attempt to establish a classless, casteless, secular society and create a new future for themselves, seemed to him to be the fulfillment of Daniel Hamilton's dream with the only difference that it was not an individual's dream. The dream had been dreamt by the very people who were trying to make it real.

These different histories of dispossession and migration thematically cluster around the cultural significance of the smaller island of Morichjhapi. Morichjhapi, with its past as the site of a major battle between a group of powerless refugees and a dominant but brutal political force, becomes cathected as the focus for the novel's main conflict. When Kanai arrives at his Aunt Nilima's home in the tide country and begins reading his Uncle Nirmal's journal of a sojourn on Morichjhapi, he asks Nilima about the significance of the place. 
The refugees, explicitly, are people without financial, commercial, or political power. Moreover, they are not only on the run from political displacement in their homes, as Nilima explains. Having arrived in India's frontier territory, the refugees soon discovered that they were not entirely welcome there either. They had thus been rounded up and taken to a 'government resettlement camp in central India... to a place called Dandakaranya, deep in the forests of Mandhya Pradesh, hundreds of kilometres from Bengal.'(118)

The revolution did not succeed. The settlers were forcibly driven out of the island. Scores of people were murdered .Women were raped and killed. The corpses were thrown either into the rivers to be eaten by crocodiles and sharks or into the tiger reserves. The rest were sent back to Dandakaranya. Their quest to reinvent their lives and make their own future proved futile.

Here from this perspective, Amitav Ghosh's historically engaged fiction presents the whole episode more or less objectively, even though the specific political actors and discourses that led to the gruesome massacre and forceful eviction of the refugees are downplayed in the novel(3).

However, it goes to the credit of Amitav Ghosh that he has dared to record, the history, which interfaces in terms of fiction, this little publicized historical event. The novelist elaborates: "Was it possible that in Morichjhapi had been planted the seeds of what might become, it not a Dalit nation, then at least a safe-haven, a place of true freedom for the country's oppressed?"(159)

This narrative act on the part of Ghosh, locating political brutality in the depths of the dark jungle, suggests that The Hungry Tide is likely to enact its own voyage into a heart of political darkness. 'They called it "resettlement," said Nilima, "but people say it was more like a concentration camp or a prison. The refugees were surrounded by security forces and forbidden to leave. Those who tried to get away were hunted down.' (118). In this way, the challenge to colonial history becomes mapped onto an ongoing struggle of the weak against the tyrannical.

This is precisely what happens to the island refugees of The Hungry Tide. With no money, power, or political influence, they are simply treated as objects to be shunted from one location to another: 'the authorities had declared that Morichjhapi was a protected forest reserve and they had proved unbending in their determination to evict the settlers. Ghosh's characters gradually learn to recognize the transient nature of the divisions between individuals-of whatever social class.

Piya and Fokir are kept apart by language and class and by the social institution of marriage; Nirmal and Nilima live side by side for years but are unknown to each other, divided by different dreams for their lives, and by a lack of respect for the other's way of embracing life. This aged couple is, in fact, reminiscent of the first one we have discussed: that of Balaram and his wife in The Circle of Reason. Recall how she was driven to distraction by Balaram's obsessions, and then imagines Nilima's words in her mouth:

It was for your sake that we first came to Lusibari, because your political involvements got you into trouble and endangered your health. There was nothing for me here, no family, friends or a job. But over the years I've built something...All these years, you've sat back and judged me. (214)

We must remember, as well, how far Piya has come, because of Fokir's generosity throughout, since she begins as a great sceptic of relationships, reading them through her own experience of her parents' relationship:

...the two of them, Fokir and herself, they could have been boulders or trees for all they knew of each other: and wasn't it better in a way, more honest, that they could not speak? For if you compared it to the ways in which dolphins' echoes mirrored the world, speech was only a bag of tricks that fooled you into believing that you could see through the eyes of another being.(159)

Note how Piya describes her proposed multi-year project in the Sundarbans: she would not need to apologize for how she had spent her time on this earth. (127)-what a sad view of life, and what a perfect way to avoid human relationships! "As with many of her peers, she had been drawn to field biology as much for the life it offered as for its intellectual content-because it allowed her to be on her own, to have no fixed address, to be far from the familiar, while still being a part of a loyal but loose knit community" (126). And yet, how different she is at the novel's end. 
SagarikaGhose 'The Shadow Lines: Review of The Hungry Tide. The Indian Express. (2004), writes of this novel that the setting evokes a series of paradoxes in the interaction of these characters:

Piya learns to love (Fokir) without language. Kanai, the translator of cultures, finds himself stripped down of all urban defences facing a tiger in a swamp. Fokir, the unlettered fisherman, falls in love with a woman who is an embodiment of science (Piya). A massive storm brings death and terminates a potentially rich love. Nirmal falls in love with Kusum and finally breaks with his armchair past. Ghosh's musings on language, translatability, on the forgotten massacre of Morichjhapi, in which dominant cultures forcibly wipe out movements from below, are deftly woven into the interactions between the characters.

If much of Ghosh's writing career has demonstrated a fascination with the passage of history, and its continuities over time, this novel seems more to underscore the fragility of our brief time on earth.This emphasis on the tenuous nature of human existence offers a powerful context for the book's concentrated focus on characters like Fokir who come into life and pass away without rippling the waves of official history.

By the end of the novel Fokir is dead, but he lives on, immortalized by Piya's project that is to be named after him. Nirmal too lives on through his diary that is to be made the basis of Kanai's masterpiece. With this, can we say that The Hungry Tide is a filmic text in the same way? Alternatively, if not in the same way, then in an equally important and related manner? There is something curiously filmic about Ghosh's dramatic plot. The storming of Morachjhapi symbolically anticipates the later storm in which Fokir is killed while assisting Piya. As this second storm reaches its climax, Piya is left clinging to the dead body of Fokir, who is in turn lashed to a tree for protection against the rage of the cyclone. From this point, Ghosh cuts to a fresh chapter: a calm river scene, the following morning. This dramatic juxtaposition of storm and serenity works, in the same way that the cutting and editing of a Film might work changing mood and atmosphere with the change of a scene. It leaves an importing question about what cannot be said in narrative, and what cannot be shown in a film. This considers us of the complex relationship that exists between writing, representation and atrocity.

The Hugry Tide, as we have seen, has two climaxes: the storming of Morachjhapi, and the storm, which destroys Fokir. Yet these local cataclysmic events exist in elision and in silence. Neither event is narrated in minutiae; rather, Ghosh employs a narrative technique of cutting from 'before' to 'after' in each case, as it to draw attention to the human limits of what can be narrated and what is unspeakable.

The perspective of the metropolitan interloper Piya, her concern and sincere effort brings financial assistance for Fokir's widow and orphaned son from other corners she also concern for the animal's welfare, no matter how well intended, is bound to seem like a luxury, when contrasted with the life histories of the villagers involved. They, like Kusum, have deep-rooted reasons to fear the tiger and this manifests itself in a violent willingness to seize the rare opportunity to kill one of the animals. The juxtaposition of these two scenes and perspectives therefore informs our understanding of the novel's main theme of dispossession: How is it possible for supposedly well-meaning people to value conservation over human life? Ghosh does not reject natural conservation as such, but he does open a perspective on its significance, which could only be found in the tide country, among the dispossessed. Here, Ghosh makes an ironic point about the values of the educated visitor, as contrasted with the supposedly superstitious values of the dwellers of the impoverished tide country.

\section{CONClusion}

The Hungry Tide is a stunning novel of humane breadth which is epic in scope, sophisticated in its observations of people and their milieu, poetic in its evocation of the 'terrible beauty' of the Sundarbans. Although the book focuses on certain issues of global concern, it offers no easy solutions. Amitav Ghosh seems, as always, to be more interested in people than in issues. His book is about the people of the Sundarbans and their heroic struggle for survival. His greatest strength lies in the way he maps the geography of the human heart and examines the nature of man's identity. Thus, Amitav Ghosh allows the country of the hungry tide to break down the barriers of his characters and their society. 
In an interview with Sheela Reddy, 'Writing through Turmoil,' the Outlook New Delhiin 2002, Ghosh had remarked: "My fiction has always been about communities coming unmade or remaking themselves." (5) The Hungry Tide is the story of one such community of people who, having come unmade from their ancestral roots, try to remake themselves in a place where, as Nirmal writes in his notebook, 'transformation is the rule of life.' After finishing this riveting novel, the readers too feel that they have made an imaginative journey to the tide country and that the experience has remade them. According to John C. Hawley's observation that The Hungry Tide "shares Ghosh's concern for the individual against a broader historical-or even, in this case, geographical -backdrop" (3) may be relevant in this context.

\section{REFERENCES}

The Hungry Tide. New Delhi: Ravi Dayal, 2004. Print.

Chambers, Claire. The Relationship between Knowledge and Power in the Work of Amitav Ghosh Leeds, 2003. Print.

Dixon, Robert. 'Travelling in the west: The Writing of Amitav Ghosh'. The Journal of Commonwealth Literature. 31.1 (1996):3-24. Print.

Ghose, Sagarika. 'The Shadow Lines: Review of The Hungry Tide'.The Indian Express. 27 June 2004. <http://www.indianexpress.com/full_story.php?content_id=49600>

Ghosh, Amitav: An Introduction; Contemporary Indian Writers in

English series; Foundation Books, New Delhi: 2005, 131-32. Print.

Gibert, Harriet. 'Ghosh's Words of Change'. 27 July 2000.

<http://www.bbc.co.uk/worldservice>

Graff, Gerald. 'Cultural Criticism Redrawing the Boundaries, ed

Stephen Greenblatt and Giles Gunn. 1996: 421. Print.

Hemmadi, Usha. 'Amitav Ghosh: A Most Distinctive Voice' in Nilufer E. Bharucha and Vrinda Nabar (eds) Mapping Cultural Spaces. 58-60.

Hickling, Alfred. 'Islands in the Stream: Review of The Hungry Tide'. The Guardian Weekly. 19 June 2004. <http://www.books.guardian.co.uk/print.>

'The March of the Novel Through History: The Testimony ofmy Grandfather's Bookcase'. Kunapipi 19.3 (1997): 2-13. Reprinted in Kenyon Review. 20. 2 (1998): 13-24.

Reddy, Sheela. 'Amitav Ghosh: Writing Through 'Turmoil'. (in Out Look) 19 August 2002. http://www.worldpress.org

\section{AUTHOR'S BIOGRAPHY}

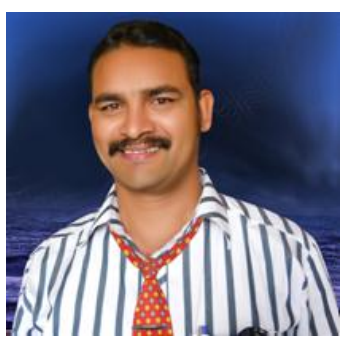

Dr.Venkateswarlu Yesapogu awarded his $\mathrm{PhD}$ degree in (2012) in the contemporary Indian fiction at the Acharya Nagarjuna University, GUNTUR, Andhra Pradesh, India, his M.A., M.Phil, also happened in the English literature. He is now teaching English Literature and Phonetics in V.V. \&M. Degree College ONGOLE. He became the youngest Principal FAC by virtue of awarded PhD and seniority among existing staff since 2009. His teaching is on main research interests including teaching of Phonetic Science as well as communication skills. He has recently published two books. The first entitled "The Fictional World of Amitav Ghosh" with ISBN 9789382186397; and published several other articles in reputed international journals. He has participated National and International seminars/conferences. 